\title{
Menopause Status not Evaluated
}

National Cancer Institute

\section{Source}

National Cancer Institute. Menopause Status not Evaluated. NCI Thesaurus. Code C159772.

The menopause status has not been evaluated. 